\title{
Paisaje y patrimonio en el valle de Lecrín
}

\author{
Miguel Ángel Sánchez del Árbol | Dpto. de Análisis Geográfico Regional y Geografía \\ Física, Universidad de Granada \\ URL de la contribución <www.iaph.es/revistaph/index.php/revistaph/article/view/3914>
}

\section{RESUMEN}

El emplazamiento geográfico del valle de Lecrín, entre las sierras Nevada $y$ de las Albuñuelas en sus flancos oriental y occidental, y entre la vega de Granada y el bajo río Guadalfeo-costa, en los límites septentrional y meridional, respectivamente, ha condicionado, de forma muy significativa, tanto la multiplicidad de hechos y procesos naturales aquí acaecidos, como su larga y conspicua historia de ocupación y manejo humanos. Espacio ora de encuentro, ora de separación de diversas realidades territoriales, comparte características naturales y culturales con las citadas entidades aledañas, pero asimismo ofrece un repertorio único de singularidades.

Su estratégica situación geográfica, así como la disponibilidad de recursos biológicos, climáticos, hídricos y minerales de diversa índole han propiciado una temprana y sostenida ocupación humana, como lo demuestra la prolija presencia de vestigios arqueológicos de numerosas etapas y culturas, desde, al menos, el Paleolítico medio. Igualmente cabe destacar la pervivencia de diversas y particulares expresiones etnológicas, especialmente las de carácter intangible, relacionadas con gastronomía, formas de aprovechamiento de los recursos del entorno, festividades y leyendas, sin que falten las de carácter material, en especial ciertas formas constructivas de viviendas, de instalaciones agropecuarias, de bancales 0 de conducciones hidráulicas.

A su vez, el valle de Lecrín ofrece un mosaico paisajístico extraordinario a partir de una variada combinación de diferentes usos del suelo y manejo de recursos en el contexto de numerosos y diversos microclimas, formas de relieve, manifestaciones hídricas, tipos de suelos y comunidades vegetales y faunísticas. Un paisaje, en fin, que representa uno de sus más relevantes recursos y señas de identidad territoriales.

\section{Palabras clave}

Granada (Provincia) | Paisaje | Patrimonio cultural | Patrimonio natural | Valle de Lecrín | 


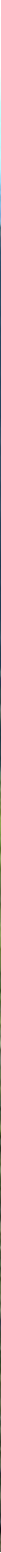

Encajamiento del río Dúrcal en las dolomías mesozoicas aguas abajo de Cónchar | foto Miguel Ángel Sánchez del Árbol, de todas las imágenes del artículo si no se indica lo contrario 
Poblado en la actualidad por algo más de veinte mil habitantes censados, y unos pocos miles en condición de transeúntes o de residentes temporales, el valle de Lecrín se encuentra entre las comarcas granadinas en retroceso demográfico desde hace medio siglo, así como de más reducida densidad de población, superando los veinte puntos po debajo de la media provincial. Sólo dos municipios, Dúrcal y Padul, ambos situados en el recorrido de la autovía A-44 Bailén-Motril son ajenos a esa tendencia, mostrando unos valores demográficos superiores a las cifras medias provinciales, así como unas dinámicas socio-económicas, de transformación de usos del suelo y urbanísticas más activas que las registradas en el resto del valle de Lecrín (VILLEGAS MOLINA; SÁNCHEZ DEL ÁRBOL, 2008)

2

El repertorio de manifestaciones tectónicas y geomorfológicas presentes en el ámbito es muy amplio: horts y fosas, fracturas y fallas pliegues, conos aluviales, travertinos, turberas, abarrancamientos profusos, desfiladeros y gargantas fluviales, geoformas kársticas amplias series estratigráficas, etc.

\section{RASGOS GEOGRÁFICOS DEL VALLE DE LECRÍN}

El valle de Lecrín es una entidad territorial constituida por ocho términos municipales (Albuñuelas, Dúrcal, El Pinar, El Valle, Lecrín, Nigüelas, Padul y Villamena) que se localizan en una de las diversas depresiones que orlan Sierra Nevada, concretamente la de su flanco occidental, a la vez la de mayor superficie y complejidad física, biológica y antrópica. Espacio de transición entre los dos más dinámicos, poblados y pujantes de la provincia granadina -la aglomeración metropolitana de Granada y el litoral centro-occidental con capitalidad en Motril-, el valle de Lecrín ha desarrollado funciones territoriales diversas según períodos históricos y modelos socio-económicos, en algunos momentos de forma relativamente pujante. No obstante, en las últimas décadas ha mantenido su condición básica de comarca agrícola, a la vez que ha ejercido funciones productivas, industriales, residenciales y de turismo rural subsidiarias de los otros dos ámbitos territoriales citados. Uno de los hechos que avalan esta situación es su evolución demográfica regresiva ${ }^{1}$.

Por otro lado, son diversos y de gran trascendencia los hechos naturales que marcan la impronta de este territorio, especialmente sus componentes geomorfológicos e hidro-climáticos. En efecto, una evolución geológica larga y compleja, afectada por diversas etapas generadoras de fenómenos tectónicos (orogenia Alpina), la intercalación de materiales de diverso origen (marino, lacustre, continental), composición mineral y resistencia frente a los procesos de desgaste, así como la incidencia de variadas morfogénesis, desde las propias de altas cumbres serranas a las de laderas medias y fondos de valle, etc., han hecho que el relieve de este ámbito sea uno de los más complejos y polimórficos de Andalucía ${ }^{2}$. Los efectos de este marco topográfico son múltiples, pero cabe incidir en las dificultades impuestas a las comunicaciones internas y externas hacia Granada, la Costa y las Alpujarras por los numerosos barrancos que atraviesan el valle de Lecrín. Expresión material de la constante lucha humana por superar estos y otros escollos naturales es la presencia de abundantes obras de ingeniería civil de diferentes épocas, materiales empleados, técnicas constructivas y aspectos estéticos, generando un paisaje plagado de puentes, viales, estructuras de contención, etc., sobre todo en la angostura del río Ízbor a la altura de Acebuches, en el barranco de Tablate y en el río Dúrcal (SÁNCHEZ DEL ÁRBOL; GARRIDO CLAVERO, 2015).

\section{EL VALOR PAISA JíSTICO DEL VALLE DE LECRÍN}

Como en otros muchos territorios, la mano del hombre ha generado degradación o destrucción en componentes físico-ambientales del valle de Lecrín, pero aquí resulta más significativa la diversificación y complejización que 
ha supuesto la injerencia humana, además del hecho de presentarse, en muchos de los escenarios, una excelente integración entre manifestaciones naturales y culturales. A su vez, determinados elementos patrimoniales coadyuvan a cualificar escenas paisajísticas del ámbito, como es el caso de árboles centenarios o formaciones geológicas monumentales; manantiales, corrientes y láminas de agua; castillos y otras estructuras defensivas; iglesias, ermitas, casonas, palacetes, cortijos, molinos hidráulicos y otras construcciones religiosas y civiles; acequias, acueductos y puentes históricos; yacimientos arqueológicos... De hecho, el patrimonio cultural tanto material como inmaterial del valle de Lecrín es muy variado, cuantioso y socialmente aprovechable ${ }^{3}$, en gran medida gracias a la confluencia de dos importantes factores geográficos: la suficiencia de recursos naturales para satisfacer las necesidades de las sociedades de cazadores y agro-ganaderas del pasado (numerosos grandes manantiales y cursos de agua, fertilidad del terreno, abundancia de vegetación y fauna...) y su condición de pasillo natural entre la costa y la parte centro-meridional de la península ibérica que ha supuesto un activo eje de comunicaciones desde la Prehistoria, llegando a adquirir gran importancia a partir de la época ibero-romana. En cualquier caso, la conjunción del marco natural y de las adaptaciones humanas en el valle de Lecrín hacen del paisaje resultante uno de sus más relevantes recursos; asimismo gran parte de su actual atractivo como espacio predominantemente agrícola, residencial y turístico-rural se basa en el paisaje, a cuyos característicos rasgos y a la calidad escénica de numerosos espacios hay que añadir su elevada perceptibilidad media ${ }^{4}$.

Los diversos y específicos escenarios paisajísticos identificables pueden agruparse a partir de las dos grandes unidades definidas por la estructura física de este espacio geográfico.

El valle alto presenta una fisonomía de extensa semillanura separada de Sierra Nevada por una muy marcada línea de falla de casi una veintena de kilómetros (falla de Nigüelas, declarada monumento natural). El paisaje generado presenta fuertes contrastes, pues al borde montañoso se le contraponen bruscamente las rampas (conos y abanicos aluviales) y la planicie contiguas; a lo que se suma la diversidad de tonalidades surgida a partir de las diferencias edáficas y vegetales, así como de cultivos implantados en una y otra unidad topográfica.

Así, mientras que en las laderas predomina el jaspeado de un monte bajo, de disposición rala en amplias superficies y puntualmente arbolado (pinos sobre todo, aunque también hay sabinas, encinas y otras especies), en las rampas predominan los cultivos leñosos (sobre todo almendros, cuya floración primaveral enriquece cromáticamente el paisaje) y en el llano la tónica habitual es la presencia de manchas de gran verdor y humedad, de origen agrícola (olivos, frutales y herbáceos de regadío) o palustre (SÁNCHEZ DEL ÁRBOL, 2009).
3

Entre las múltiples posibilidades de gestión del patrimonio cultural, desde la protección hasta la puesta en valor, el valle de Lecrín ofrece la posibilidad de potenciarlo a través de muy diversas rutas temáticas orientadas a funciones didácticas y turísticas: rutas arqueológicas, de la transhumancia, hidráulicas, de los castillos y fortalezas nazaríes, de los diversos sistemas agrícolas históricos, de la guerra de los moriscos (por los lugares mencionados en los textos históricos), de las tipologías constructivas adaptadas al entorno de los diferentes pueblos, de los jardines históricos, etc. (COMPÁN VÁZQUEZ; SÁNCHEZ DEL ÁRBOL, 2009).

4

Este buen nivel de perceptibilidad del paisaje está favorecido por la concurrencia de: moderadas dimensiones espaciales, escalonamiento topográfico, numerosos potenciales puntos de observación elevados que jalonan el perímetro de la fosa tectónica, predominio de días despejados, relativa densa red viaria, diagonal trazado de la autovía A-44, abundancia de núcleos de población... 


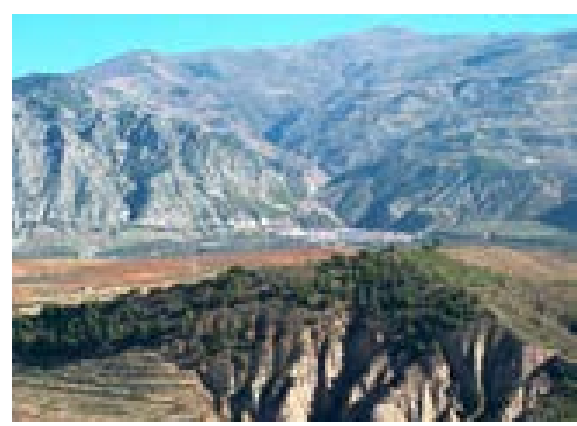

Escalonamiento orográfico desde los límites del valle alto hasta la cumbre del pico Caballo (en el centro del encuadre, Nigüelas) | foto Alejandro Sánchez Baca
Inclusión de la laguna en el Parque Natura de Sierra Nevada en 1989, así como su catalogación como humedal de importancia internacional (Humedal Ramsar) y como Zona de Especial Conservación (ZEC) desde 2012

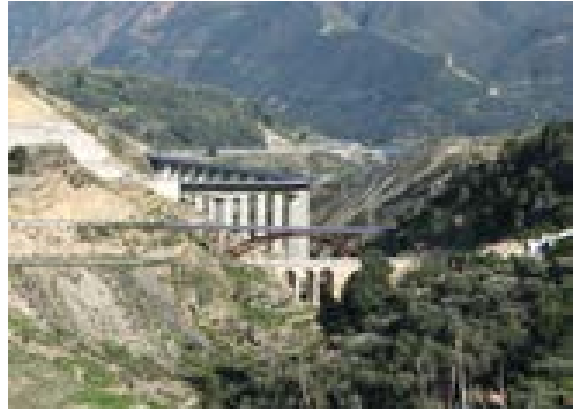

Acumulación de puentes y viales volados en la cerrada del río Ízbor junto al núcleo de Acebuches

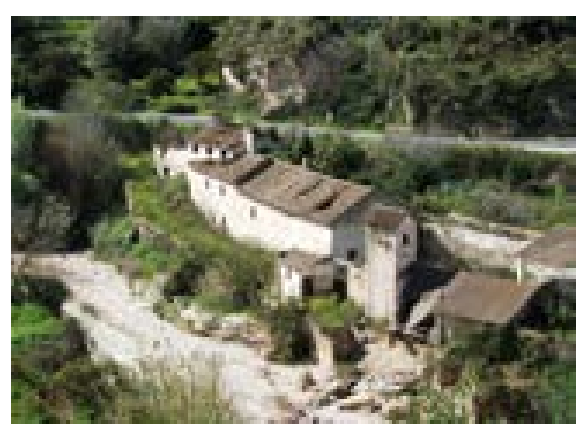
Albuñuelas
Restos de antiguo molino hidráulico junto al río

En la parte septentrional del valle alto se ubica la "cubeta de Padul", caracterizada por recibir los aportes hídricos de las grandes extensiones limítrofes, donde la configuración tectónica, estratigráfica y litológica propicia la abundancia de fuentes y manantiales de los que brotan caudales muy importantes, como Ojo Oscuro, Agia, los Molinos, Povedano, Cijancos... (RUBIO CAMPOS; BEAS TORROBA; LÓPEZ GETA et ál., 2006).

En la parte más deprimida de esta unidad topográfica se está recuperando en los últimos años parte de la superficie hídrica de la que fue una extensa laguna, cuyas aguas son drenadas con auxilio de zanjas o madres, que fueron excavadas en el siglo XIX para, justamente, desecar el área con objeto de cultivarla, así como para contrarrestar epidemias endémicas como el paludismo (ORTEGAALBA, VILLEGAS MOLINA; SÁNCHEZ DEL ÁRBOL, 1990).

En la actualidad, la laguna de Padul constituye el humedal de tipo turbera más meridional del continente europeo y cuenta con una elevada productividad biológica fundamentada en la presencia de uno de los carrizales más extensos de la península ibérica que, junto con la superficie de aguas libres, constituye el hábitat de numerosas aves acuáticas y de herpetos (ARIAS GARCíA, 2016). El hallazgo de restos de mamut lanudo añade asimismo interés paleontológico, que, unido a los valores ambientales y paisajísticos, han acreditado su protección pública ${ }^{5}$. Observado desde posiciones adecuadas, este espléndido escenario no deja indiferente: los escarpados perfiles orográficos sirven de telón de fondo al feraz e hídrico tapiz de la cubeta tectónica, donde, ni tan siquiera las lacerantes canteras de zahorra en parte clausuradas, ni las cada vez más prolíficas construcciones periurbanas de Padul, ensombrecen suficientemente el atractivo de este paisaje (HERNÁNDEZ DEL ÁGUILA; SÁNCHEZ DEL ÁRBOL, 2016). Hacia el sureste, y una vez flanqueado el profundo encajamiento del río Dúrcal, recubierto por arboledas caducifolias, se localiza una extensa llanada pliocuaternaria tras la sedimentación de ingentes volúmenes de derrubios arrastrados desde las laderas orográficas, que asimismo han formado una compleja sucesión y yuxtaposición de conos y abanicos aluviales. 


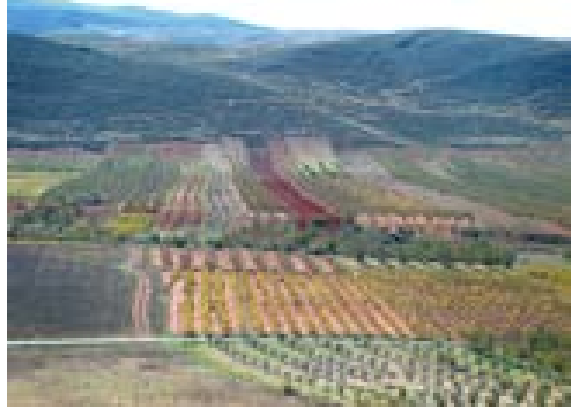

Diversidad cromática propiciada por la yuxtaposición de diferentes suelos y cultivos en el borde oriental de la meseta de Albuñuelas

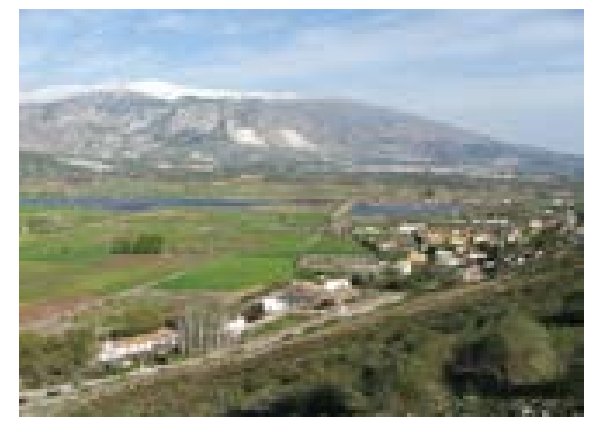

El histórico camino de los Molinos flanquea la cubeta de Padul por su margen suroccidental

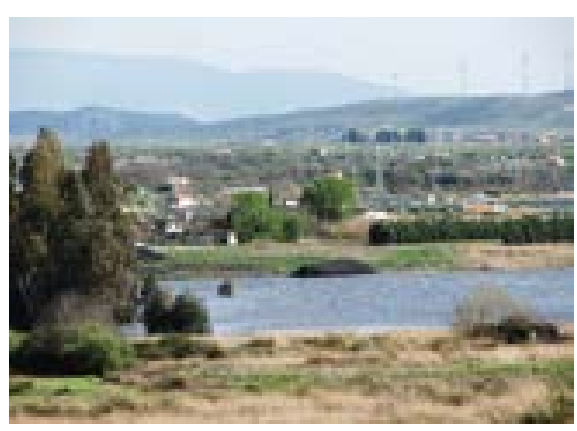

Sector recuperado por la laguna de Padul en las inmediaciones de la turbera de Aguadero

La importante expansión urbana de Padul y Dúrcal, la abundante presencia de edificaciones plurifamiliares y la utilización de materiales, texturas y colores muy heterogéneos, la proliferación de naves industriales, la incidencia de sucesivas infraestructuras viarias (en especial la autovía A-44), etc., han transformado notoriamente el escenario predominantemente rural en las dos o tres últimas décadas. No obstante, en espacios periféricos de esta unidad se emplazan algunos de los núcleos que mejor han conservado su original entramado morisco, incluso parte de la tipología edificatoria, así como una más genuina integración con el parcelario agrícola y con el sistema de acequias y caminos: Nigüelas, Acequias, Cónchar y, en alguna menor medida, Cozvíjar.

El valle bajo presenta una fisonomía más acorde con la imagen más característica de "valle": laderas opuestas inclinadas hacia un fondo lineal por donde discurre el río que drena toda la comarca, el Ízbor. El emplazamiento de este sector entre las cálidas aguas del mar Mediterráneo y arelativo resguardo por la envolvente orográfica, en una exposición muy soleada, propicia que disfrute de un bonancible clima durante la mayor parte del año. Es de destacar la pervivencia más extendida en esta unidad de referentes paisajísticos de carácter rural: pequeños núcleos de población bien integrados en el espacio, agricultura tradicional, red viaria de pequeña sección y en general adaptada a la topografía, abundancia de sotos junto a los cursos de aguas, etc. Es característica común de la mayoría de los asentamientos del valle, y especialmente los de este sector más deprimido, su estructura de origen andalusí, parcialmente laberíntica, con las edificaciones unidas materialmente unas a otras formando conjuntos separados por callejas, a menudo angostas y sinuosas. En general, las recientes intervenciones edificatorias en la mayor parte de los núcleos de la comarca, especialmente los del valle bajo, han consistido en el relleno de sus vacíos urbanos y en la renovación del patrimonio existente, por lo que su escaso o acotado crecimiento y un cierto grado de sensibilidad en las actuaciones emprendidas han contribuido a la conservación de la imagen tradicional de estos asentamientos (DEL CASTILLO SÁNCHEZ; MEDINA BARBERO; RADIAL MOLINA et ál., 2010). 


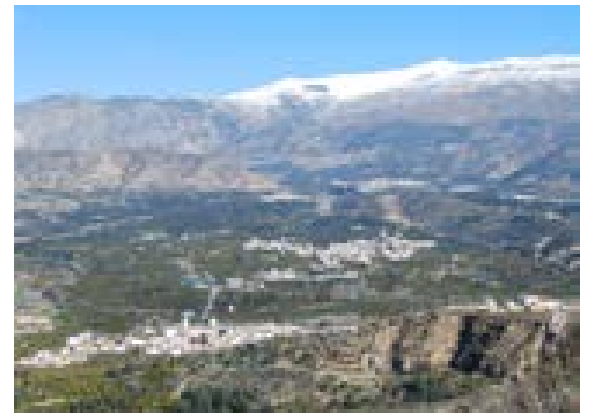

En el corazón del valle bajo se intercalan los pueblos blancos y los verdegueantes cultivos de regadío | foto Juan Garrido Clavero

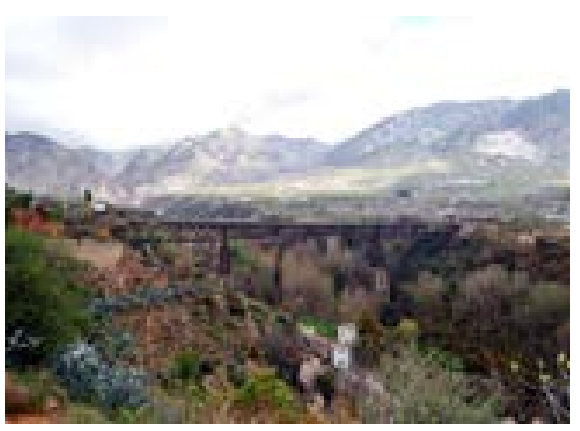

El puente de Lata sobre el río Dúrcal. Al fondo, Los Alayos y sierra de El Zahor

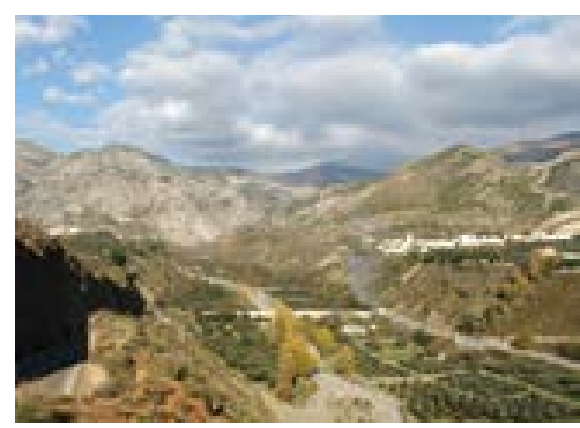

El núcleo de Acequias sobre el escalón de la margen izquierda del río Torrente
En la zona medular se localiza la mayor parte de los núcleos de población (Béznar, Melegís, Mondújar, Murchas, Restábal, Saleres, Talará y otros menores), así como su espacio agrícola más feraz y genuino. Las condiciones climáticas, en combinación con el multisecular y complejo sistema de riego, han propiciado la proliferación de un verdadero vergel agrícola sustentado en cultivos termófilos irrigados, como chirimoyos, aguacates, nísperos, hortalizas y, sobre todo, agrios (naranjos y, en menor proporción, limoneros). En numerosas explotaciones, sobre todo las peor orientadas a mediodía, los cítricos se cultivan en promiscuidad con enormes olivos multicentenarios, que les propician resguardo frente a eventuales heladas persistentes o tardías (VILLEGAS MOLINA, 1972; COMPÁN VÁZQUEZ, 2000).

El sector suroccidental del valle de Lecrín coincide, en general, con la cuenca del río Albuñuelas. Tajos excavados en materiales calcáreos acompañan los márgenes del curso fluvial durante varios kilómetros y uno de sus principales afluentes (barranco de Luna) ha horadado tanto la capa de calizas como una de yesos subyacente, ofreciendo una singular sucesión estratigráfica. Por su lado, a la interesante disposición prolongada a media ladera del núcleo de Albuñuelas, se añade la infrecuente pervivencia de algunas casas inclinadas por efecto de terremotos y del desplazamiento de estratos subyacentes. Más al sureste, el embalse de Béznar marca la fisonomía y parte de las condiciones ambientales de todo el valle bajo, destacando paisajísticamente la propia lámina de agua y su irregular perímetro marcado por sucesivos entrantes, salientes y prominentes tajos generados por una prolija sucesión de barrancos.

Un último escalón topográfico se produce en el encajamiento del río Izbor, que discurre desde la citada presa, al pie del núcleo de Pinos del Valle, hasta la confluencia con el río Guadalfeo. En esta angostura se contrapone de forma drástica el paisaje de ambas vertientes: la izquierda, orientada al sur, ha sido muy transformada en la última década con la implantación de la autovía A-44, aerogeneradores eólicos y otras infraestructuras; la ladera derecha, orientada al norte y de agreste perfil, escenifica la secular adap- 


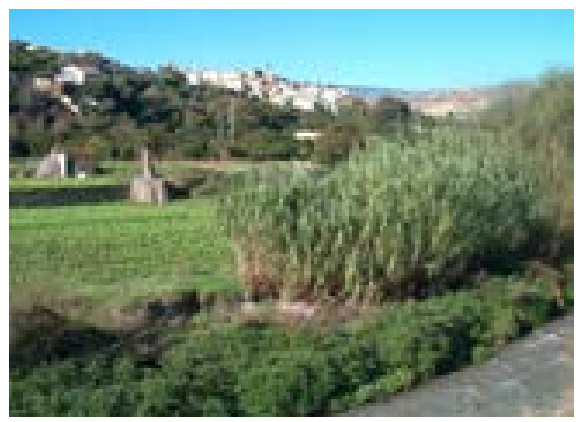

Localización de Restábal en un entorno dominado por cultivos de cítricos, huertas y plantas ribereñas

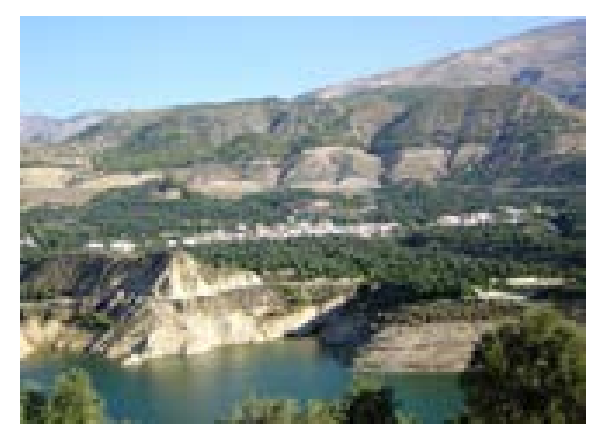

Zona central del embalse de Béznar, donde los bordes presentan acusados perfiles topográficos

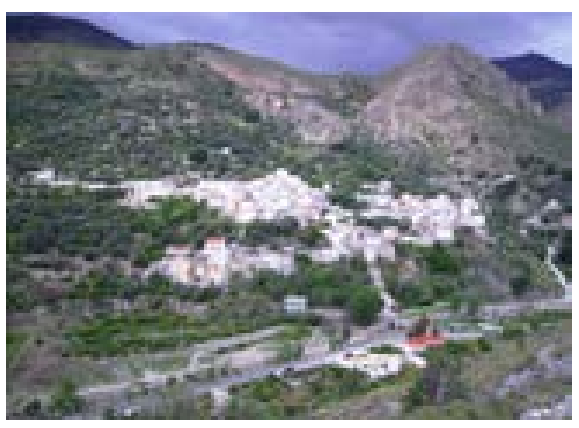

El núcleo de Ízbor, declarado BIC, rodeado de cultivos arbóreos sobre terrazas practicadas en la acusada ladera

tación que el hombre ha hecho de estas inclinadas vertientes, tanto en la configuración escalonada de los asentamientos (Acebuches e Ízbor), como en su puesta en cultivo a través de un complejo sistema de terrazas, en los que con frecuencia se han aprovechado los obstáculos rocosos -como es el caso de grandes bloques desprendidos de zonas más elevadas- para sustentar las pequeñas parcelas, así como de un dificultoso trazado de las acequias, algunos de cuyos tramos han sido excavados en la dura piedra (SÁNCHEZ DEL ÁRBOL, 2012). 


\section{BIBLIOGRAFÍA}

- ARIAS GARCíA, J. (2016) Identificación, caracterización y cualificación de los paisajes de las grandes cuencas endorreicas de Andalucía: ensayo metodológico para la implementación del Convenio Europeo del Paisaje en sistemas lacustre-palustres. Granada: Editorial Universidad de Granada <http://digibug.ugr.es/handle/10481/40944> [Consulta: 13/07/2017]

- CAStillo SÁNCHEZ, G. DEL; MEDINA BARBERO, R.; RADIAL MOLINA, J. F. et ál. (2010) Criterios para la intervención en el paisaje urbano y rural de los municipios del Valle de Lecrín (Granada). Diputación Provincial de Granada, 2010, 234 p.

- COMPÁN VÁZQUEZ, D. (2000) Valle de Lecrín. Revista ADOS. Turismo Interior, n. ${ }^{\circ} 16,2000$, pp. 14-22

- COMPÁN VÁZQUEZ. D.; SÁNCHEZ DEL ÁRBOL, M. A. (dir.) (2009) Estudio de Promoción Local en la comarca del Valle de Lecrín. Bases y estrategias para el desarrollo de ocio en la naturaleza en el Valle de Lecrín. Convenio de Colaboración entre el Consorcio para la Unidad Territorial de Empleo, Desarrollo Local y Tecnológico (Junta de Andalucía) y el Grupo de Investigación Paisaje, Medio Ambiente y Ordenación Territorial (Universidad de Granada), 2009, 285 p.

- HERNANDEZ DEL ÁGUILA, R.; SANCHEZ DEL ÁRBOL, M. A. (2016) El paisaje de la provincia de Granada. En ROSÚA, J. L.; CORTÉS, B. (ed.) Rutas paisajísticas por el viñedo de la provincia de Granada. Editorial Universidad de Granada, 2016, pp. 21-54

- ORTEgA ALBA, F.; VILlEgAS MOLINA, F.; SANCHEZ DEL ÁRBOL, M. A. (1990) Le secteur méridionel de la haute Andalusie. Déprise agricole et autres changements visibles. En Géographie d'une Espagne en mutation. Prospections aériennes II. Madrid: Publicaciones de la Casa de Velázquez, 1990, pp. 95-114

- RUBIO CAMPOS, J. C.; BEAS TORROBA, J.; LÓPEZ GETA, J. et ál. (ed.) (2006) Guía de manantiales de la provincia de Granada. Una visión sobre su origen y naturaleza. Granada: Diputación de Granada e Instituto Geológico y Minero de España, 2006, pp. 160-165

- SANCHEZ DEL ÁRBOL, M. A. (2009) El medio bío-físico de la Depresión de Padul (Valle alto de Lecrín). En GÓMEZ ZOTANO, J.; ORTEGA ALBA, F. (ed.) El Sector Central de las Béticas: una visión desde la Geografía Física. Granada: Universidad de Granada, 2009, pp. 299-322.

- SANCHEZ DEL ÁRBOL, M. A. (dir.) (2012) Acondicionamiento paisajístico de los accesos a pequeñas poblaciones. Ensayo metodológico en el Valle de Lecrín (Granada). Consejería de Fomento y Vivienda, Consejería de Agricultura, Pesca y Medio Ambiente, Centro de Estudios Paisaje y Territorio. Junta de Andalucía, 2012
- SÁNCHEZ DEL ÁRBOL, M. A.; GARRIDO CLAVERO, J. (2015) Procesos, dinámicas y afecciones del paisaje de la provincia de Granada. En ZOIDO NARANJO, F.; JIMÉNEZ OLIVENCIA, Y. (dir.) Catálogo de Paisajes de la provincia de Granada. Sevilla: Centro de Estudios Paisaje y Territorio, 2015

- VILLEgAS MOLINA, F. (1972) El Valle de Lecrín. Granada: Instituto de Geografía Aplicada del Patronato "Alonso Herrera", 1972, 348 p.

- VILLEgAS MOLINA, F.; SANCHEZ DEL ÁRBOL, M. A. (2008) Cambios paisajísticos y demográficos en el Valle de Lecrín entre 1.970 y 2.006. En BOSQUE SENDRA, J.; MARTÓN LOU, M. A. (coord.) Homenaje a Joaquín Bosque Maurell, Secretario General de la Real Sociedad Geográfica (1983-2008). Real Sociedad Geográfica, 2008, pp. 257-285 